\title{
The Design and Implementation of On-Line Multi-User Augmented Reality Integrated System
}

\author{
Hsiao-shen Wang and Chih-Wei Chiu \\ National Taichung University of Education/ Hyweb Technology Co., Ltd.
}

Taiwan

\section{Introduction}

Today's technological advancements, many innovative applications continue to emerge, and in supporting education and learning has brought many changes. With these changes, the application of using virtual reality technology has greatly different on the educational learning way compared to the traditional computer-assisted instruction. Such as abstract concepts simulation, virtual object manipulation, and interactive 3D gaming system, etc.

Through innovative technology-based learning, many learners do produce effective learning, and based on this learning effectiveness, more and more different kinds of technology-transfer medium system were requested to support learners more realistic environment in their computer-based learning system. Therefore, Augmented Reality (AR) technology gains attention in educational use because of its feature of combing real-life situation and the characteristics of virtual objects.

AR technology, through the heavy helmet display, until using the webcam and markers directly to display the result, the combing of real-life scenes and the virtual objects, on the screen, is a mature technology can be applied to assist students with learning. However, as the fixed correspondence of each maker and virtual object in AR learning system, the development of each learning courseware based on AR technology is time-consuming. Thus, how to apply software engineering methods, combined with the AR technology in education to promote more effective use of AR-based learning programs, is a subject can't be ignored.

Cooperative learning is an important way of learning in a modern educational environment. Remote cooperative learning is also an inevitable way of learning in today's internet era. Collaborative learning, from the past face to face discussions to the current Internet remote distance learning, is constantly changing, but the key is how learners can really communicate with each other between the meaning of sharing and the achievement of interaction. Based on this critical factor, many Internet-based collaborative learning systems were proposed. These systems are common, mainly through the use of the real environment among learners or the share of the virtual world generated by the system, to allow learners to engage in a dialogue between the real scenes and common virtual objects for discussion. 
However, in VR-based collaborative environments, each of the client location includes a real scene and each virtual objects generated by its VR system. How to make virtual objects of each AR system could be able shown between learners in a collaborative environment is a key problem of Cooperative learning. Thus, the purpose of the paper is to propose an online multi-user augmented reality integrated system (OMARIS) to enhance students learning in AR collaborative environment.

\section{Related work}

Using technology-based application to overcome student learning difficulties is one of important and innovative ways in education environment. Because of its virtual interactive and simulative features, the applications of using Virtual Reality (VR) technology have been widely to use and to enhance several subject domains learning effect in school, such as computer assembly, art appreciation, emotional expression, medical training and geological science (Wang, 1999, 2000,; Basori et al., 2009; Deng \& Zhou, 2009; Ni et al., 2009). With the same application of technology benefits, Augment Reality (AR) also plays a significant substantial advantage in education.

By seamlessly combining the real world with the various virtual materials, AR technology provides intuitive interaction experience to the learners. The various virtual materials, including graph, image, text, or animation, are superimposed on the reality scene based on the instructional design. With the characteristic of AR tehnology, Shelton and Hedley (2002) successfully applied the intuitive features in the nine planets learning activities which allowed students to construct and manipulate virtual objects through reality scene, and to establish their abstract scientific concepts. In recent years, AR technology has been applied in medical procedures (Rosenblum \& Julier, 2007; Samset et al, 2008), assembly design and planning (Ong, Pang, Nee, 2007), mathematical education (Lee \& Lee, 2008), Physics (Beaney \& Namee, 2008), PCDIY (Chiang et al., 2011), city maps(Jiang et al., 2011) etc. Kaufman(2006) indicated that whether teachers or students are very interested in the AR-based geometry learning activities and have positive attitude to use AR-related software in the future curriculum. However, the creation of each AR application is very time-consuming, and therefore how to reuse developed materials, including markers and virtual objects, to create a new suitable AR courseware is one of must be addressed problems for the substance of the school curriculum needs.

In AR environment, students create their understanding of the learning content through the fusion of reality scene and virtual objects, and share and discuss with other students to strengthen the significance of domain knowledge. AR simply can provide a collaborative interactive AR environment for school setting, where students can interact naturally and intuitively. AR collaboration approach can be effectively used to develop face to face interfaces. There are two kinds of AR collaborative environments which are co-located collaborative AR and remote collaborative AR (Silva, Giraldi \& Oliveira, 2003). The characteristic of co-located collaborative AR is that multiple users manipulate virtual objects within an augmented reality space in the same physical environment, and through the speech, gestures, eye contact and other means of communication of each other to share their meaning and reach the purpose of discussion.(Fig. 2.1, Fig.2.2) 


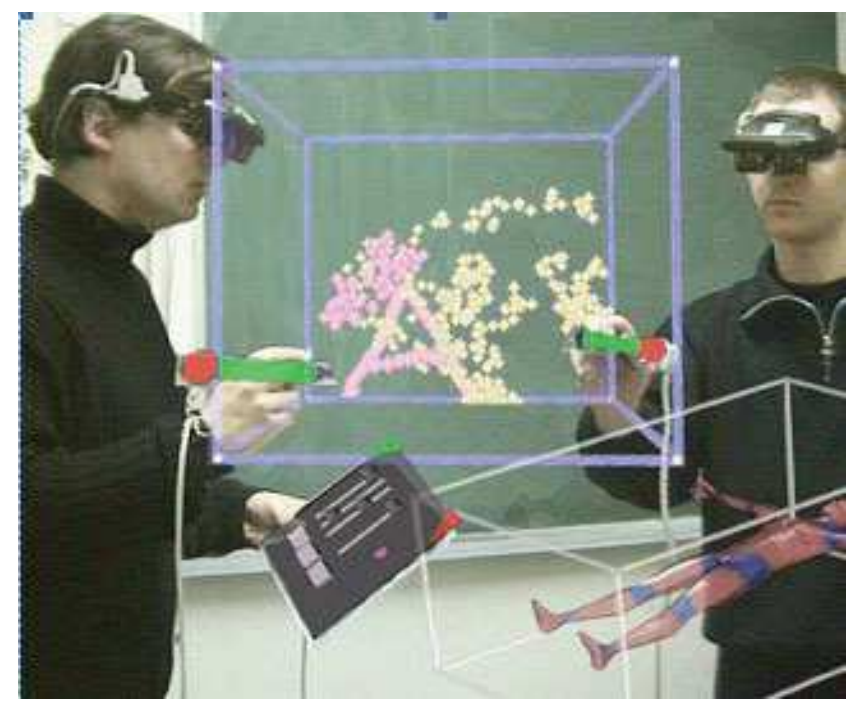

(retrieved from http://studierstube.icg.tu-graz.ac.at)

Fig. 2.1 Co-located collaborative AR.

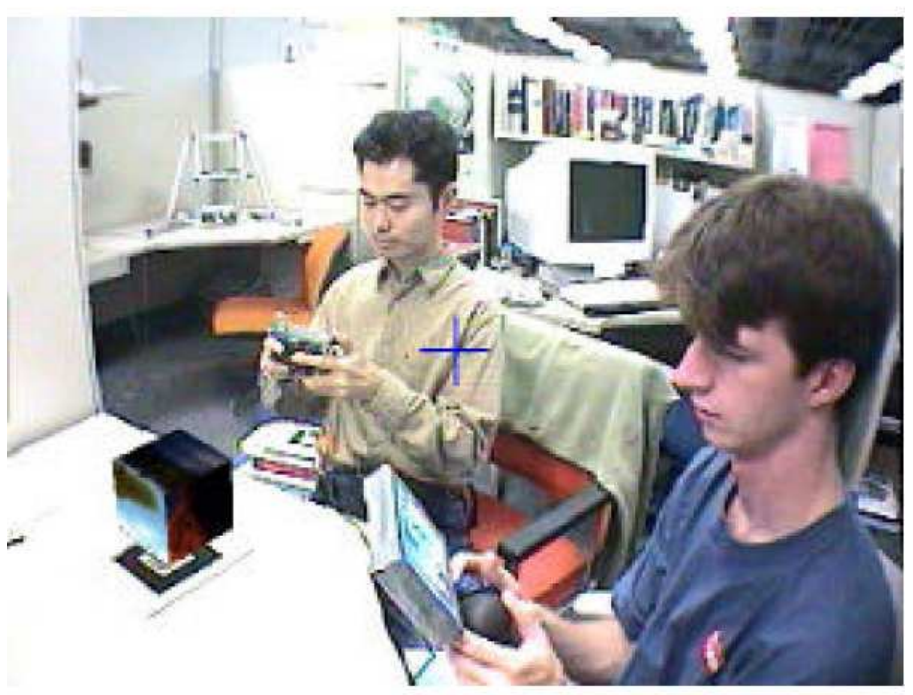

(Billinghurst et al. , 2003)

Fig. 2.2 Co-located collaborative AR2. 
While remote collaborative AR allows people in different spaces to using AR technology to share their idea for some specific virtual objects. The teachers, for instance, can use augmented reality in the remote system to guide students learning or solving problems, the students can also in different places at the same time on a specific topic of virtual objects to discuss and share their idea in the use of AR systems (Fig. 2.3).
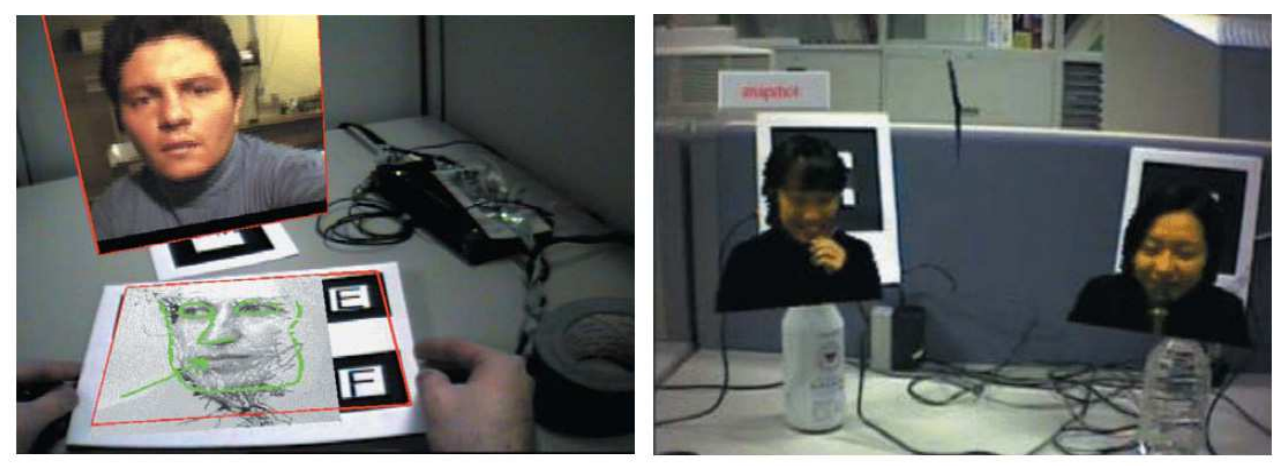

(Kato and Billinghurst, 1999)

Fig. 2.3 Remote collaborative AR.

AR has been successfully used in many learning environments, especially in cooperative interactive learning is to play its effectiveness (Lievonen et al.,2009; Shen,Ong \& Nee,2008; Quy et al.,2009; Nilsson,Johansson \& Jonsson, 2009; Godet-Bar,Rieu \& Dupuy-Chessa, 2010; Li, 2010; Dierker, Pitsch \& Hermann, 2011; Morrison et al.,2011). However, in the applications of AR collaborative environment, the learners are mostly to look from the same virtual view with an AR environment, or remote in video-conference or a network to watch and interact on a same reality scenee. How to really effectively convey the message, including image, text, and related animation, between the learners is still a major issue to enhance the learning effect in cooperation AR environment. Moreover, If both partners are in remote AR environment, the virtual objects, which are produced by the trigger of each maker of their original AR environment, do not really exist. How then to make original content that does not exist, can be delivered to distant learners to share is the key success factor in the cooperative AR environment.

Therefore, based on the concept of reuse learning materials, easy on-line AR application for students, as well as effective learning in remote collaboration AR environment, the OMARIS is developed primarily to provide teachers and students to enhance their teaching and learning effect by using AR technology in educational environment.

\section{System design of OMARIS}

The OMARIS system is mainly divided into three parts, namely, maker and object database system, personal AR learning system, as well as multi-user cooperative AR learning system. The marker and object database system is to manage markers, objects, and the links between the markerS and objects relationship. The personal AR learning system is to provide 
instructors to set up learning scenarios, and students to explore individual AR learning activities. The last multi-user cooperative AR learning system is to provide students cooperative learning activities in AR environment. Detailed system design description, as described below.

\subsection{Marker and object database system}

In general AR system, the link between the marker and the virtual object are fixed, so that the materials of the AR system are difficult to reuse. Thereby, how to manage makers, objects, and re-setup the link relationship between them is the main idea of the system. Based on the idea, the marker and object database system includes three subsystems: marker database system, object database system and marker and object matching system. The first two material database systems basically manage the uploaded materials, including marker symbols and virtual objects by authorized users. The latter one application system is based on the needs of instructional designers or general users, to set up the link between marker symbols and virtual objects in the database systems and to output as a single XML learning script file for future instructional use. After the linking relationship processed by the system, it then will be provided as the necessary materials for the further AR learning system.

\subsection{Personal AR learning system}

Since the innovation development of AR technology in education, the AR application makes the learner more motivation and substance of learning, thus providing individualized and flexible AR learning system for the learners is a key factor of the system development. Based on the idea, the personal AR learning system is designed for the instructors and learners. The instructors can select the predefine AR learning scenario, defined from previously material database system, or can customize the current AR learning script file for specific instructional needs in the personal AR learning system. The learner then can choose related topic to explore the combinational effect of the reality scenes and virtual objects in personal AR learning system.

\subsection{Multi-user cooperative AR learning system}

This collaborative learning environment is especially to provide multiple users to be able to sharing mixed AR contents from their computer system, including reality scene and virtual objects. As the virtual objects are virtual feature in the client computer system, they can't be display directly through video devices to remote collaborative computers. Therefore, in this study, Flash Actionscript 3.0 with flartoolkit AR library and PaperVision three-dimensional display library, and the point to point transmission technology of Adobe stratus are used to solve the virtual display problem.

The principle of the design methodology is when a computer via a webcam captures the marker and the reality scene, and analyses the image data of the marker by the flartoolkit library to identify the number, location, size, tilt and rotation angle and other information of the virtual object, and then hands over those data to PaperVision library to calculate the corresponding three-dimensional model presentation, and finally merges the reality scene and virtual objects as a single image. (Figure $3.1 \&$ Figure 3.2) 


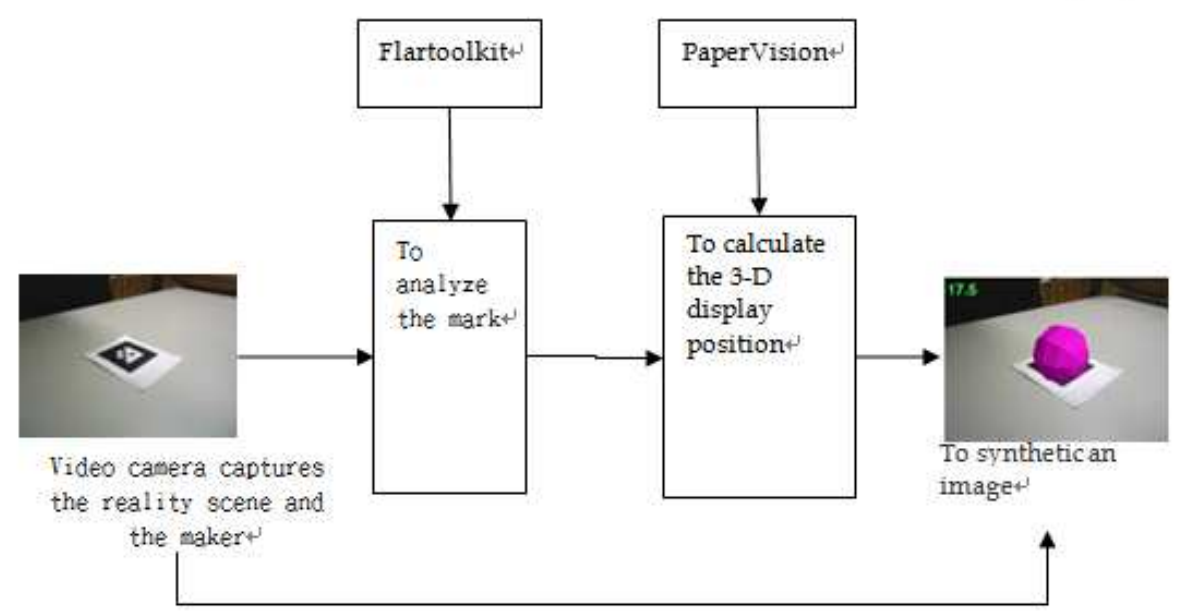

Fig. 3.1 The principle of reality scene and virtual object synthesis.

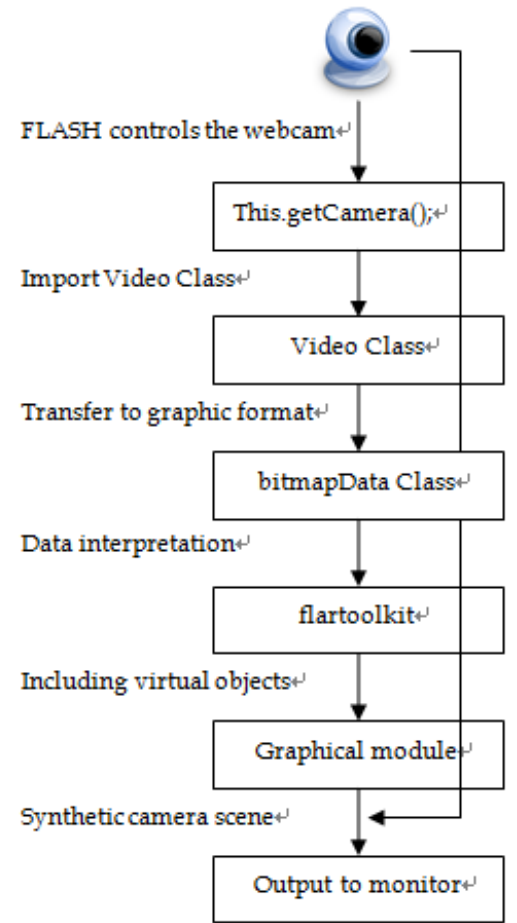

Fig. 3.2 The logic design of reality scene and virtual object synthetic process. 
As both of individual computers have synthesized their reality scene and virtual objects image, they then can, through Adobe Status point to point technology, transfer those merged data to each other. (Figure 3.3 \& Figure 3.4) Thus, the learners of OMARIS could process their cooperative learning activities to share ideas with each reality and virtual materials.

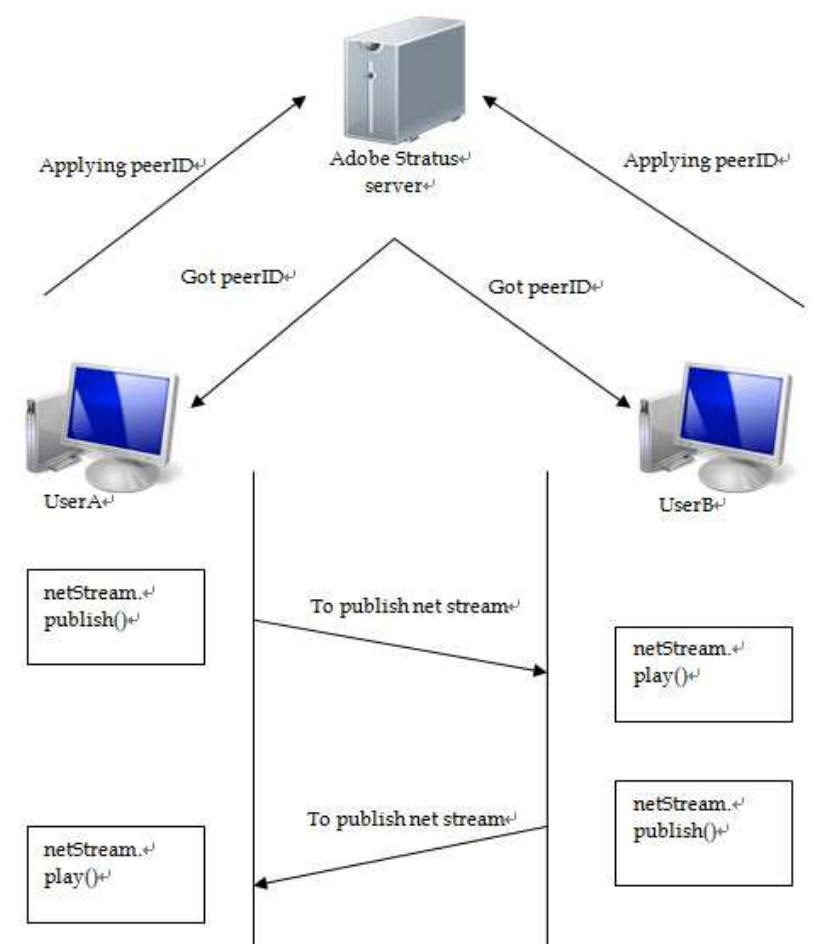

Fig. 3.3 The point to point transmission technology diagram.

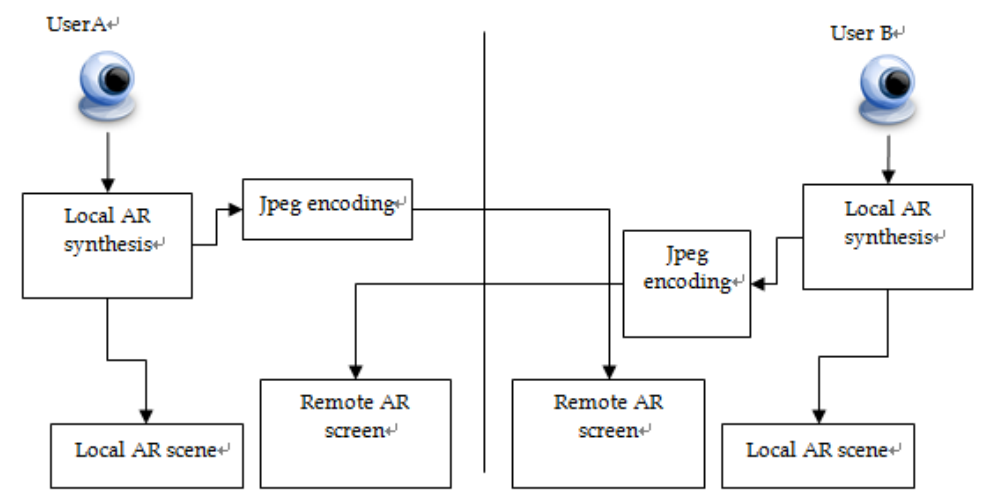

Fig. 3.4 The reality scene and virtual object encoding processing. 


\section{System implementation of the OMARIS}

The OMARIS working processes can be divided into three main parts. These parts are AR instructional database building session, which is the basis of the OMARIS, second the personal instructional session, which is used for the single user AR learning system, and finally the collaborative learning session, which is used for the multiple users AR learning system. The working processes are discussed briefly as follows.

\subsection{AR instructional database building session}

First, the system users prepare their instructional materials which include marker pictures and responding learning materials, comprising static data and 2D or 3D animation. They then enter into the OMARIS system to build the AR instructional database. Every authorized user can view the whole items of the database and manage and match their own VR instructional materials for future instructional use as shown in Fig. 4.1 and Fig. 4.2

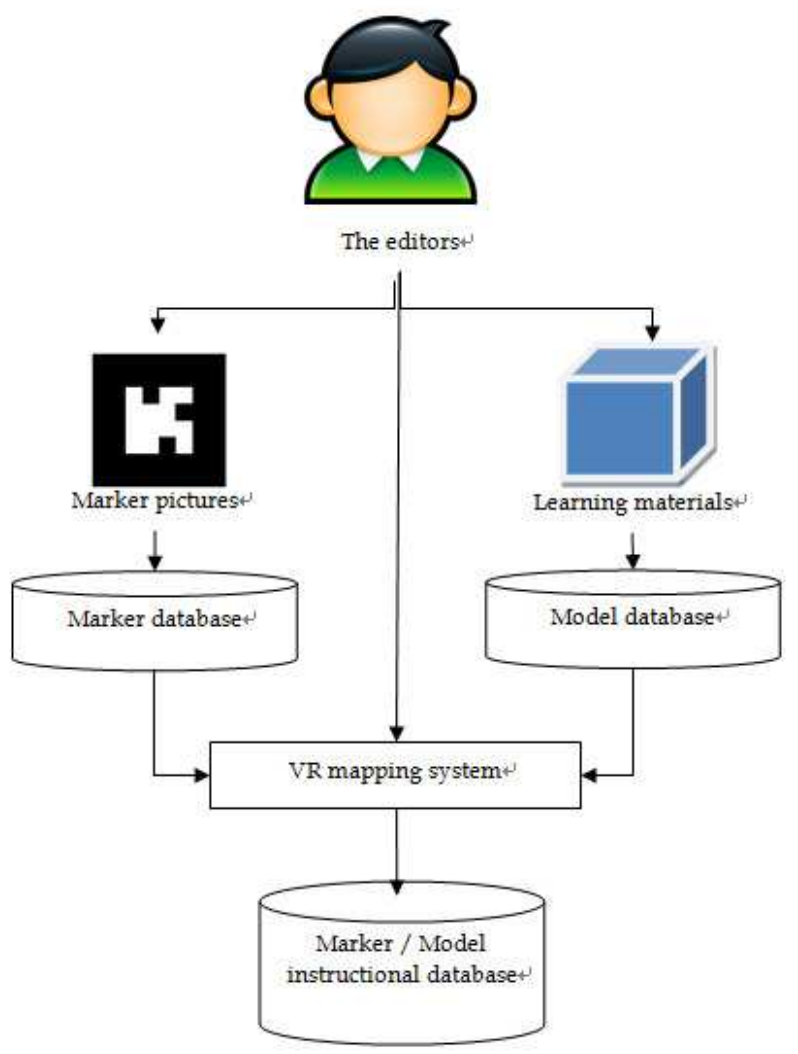

Fig. 4.1 AR instructional database diagram. 


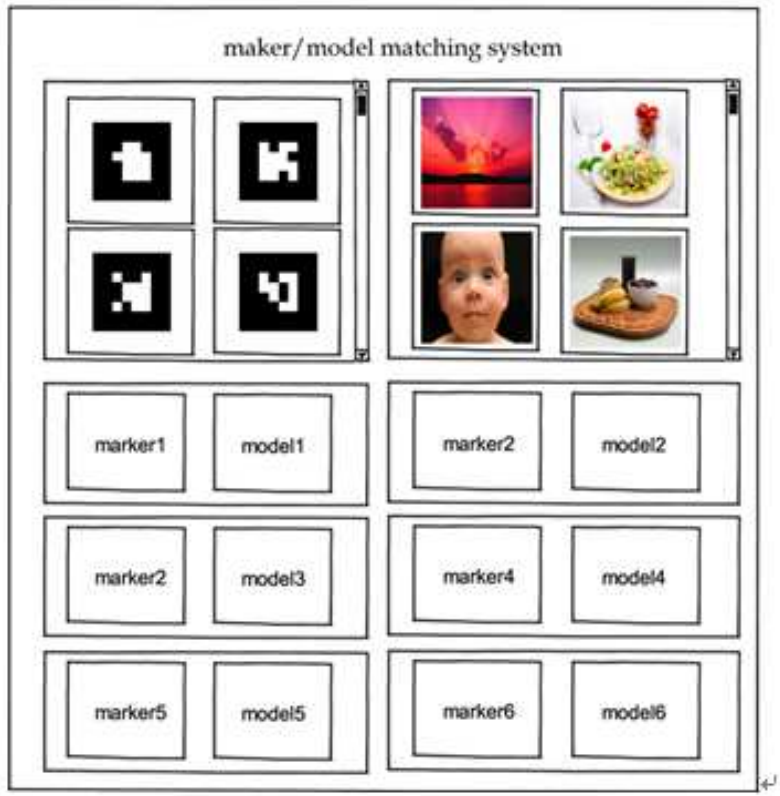

Fig. 4.2 Maker / model mapping interface.

\subsection{The personal instructional session}

During the personal instructional session, the instructor can first enter the OMARIS system to choose the predefine AR learning module, or to edit the additional learning materials for the specific learning purpose, then guides the students to login into the OMARIS system for AR-based learning activities.(Figure 4.3)
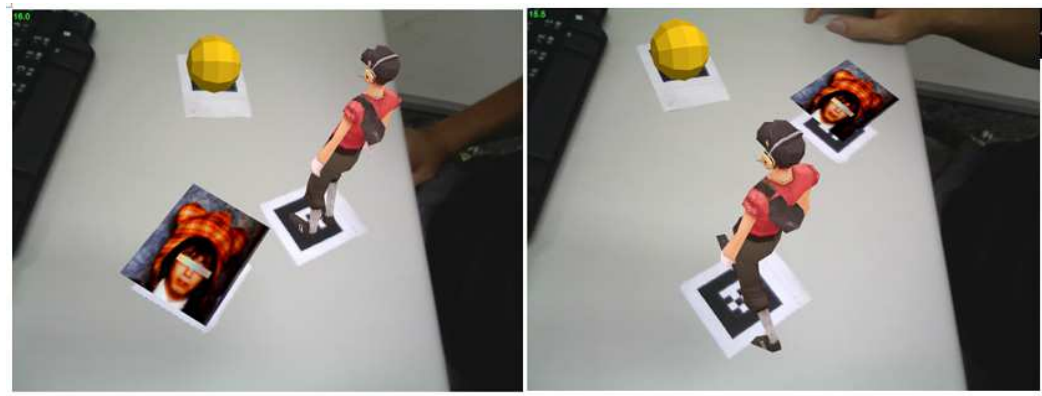

Fig. 4.3 Personal AR learning system.

\subsection{The collaborative learning session}

When learners enter the collaborative learning mode, each of them can choose same or different topic in their AR learning system. They then can send meesage to Adobe stratus to 
get their peerID for network connection. Once they take the individual's peerID, they can call each other peerID to synchronize video and audio for the cooperative activities. Through mutual learning and sharing activities, they can spread virtual objects with real-life situation in order to achieve the purpose of cooperative learning.(Figure 4.4)

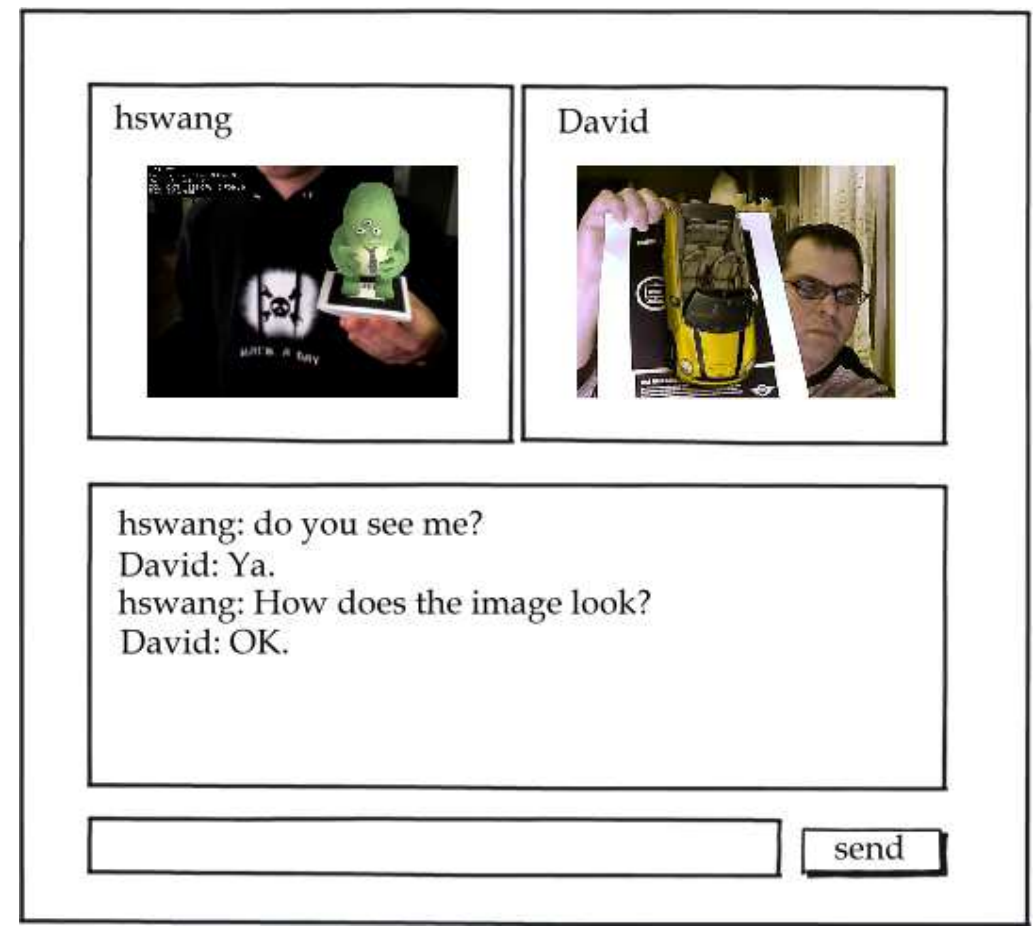

Fig. 4.4 Collaborative AR learning system.

\section{Conculsion}

As technology continues to progress and innovation, how to more effectively use in education to enhance students better productive learning is being constantly raised. Because of its creative feature of combining reality scene and virtual objects, AR technology has great attention in the use of education. Such AR based educational use, if the design of the applications considers the flexible material usability, facilitate use of equipment and the characteristics of cooperative learning, the effectiveness of the application will be more improved. The feature of the OMARIS is mainly from the educational view to use software engineering integrating technology components and learning materials to make an innovative combination in educational environment and to increase flexibly and valueadded the AR learning system in the use of school setting. In particular, the system uses multi-user remote integrating technology to on-line combine and transfer each other's real scene and virtual learning objects, which originally do not exist in a client learning environment, to both cooperative learning sides. This is different with past collaborative AR learning systems which their cooperative learning environments are processing in multiuser 
real scenes but only a same virtual situation. Thus the OMARIS system tries to offer the instructional material system, personal AR learning system and collaborative AR learning system to be more flexible reuse AR materials, the better ease use of AR application and the more completely conveying and sharing integrated message of each other during cooperative learning. With the OMARIS model, how can the creation of innovative teaching strategies to achieve greater learning effectiveness, will be more in-depth issue of the future study.

\section{References}

Amaoka,T.; Laga,H.; Yoshie, M. \& Nakajima, M.(2011). Personal space-based simulation of non-verbal communications. Entertainment Computing, Article in Press, Corrected Proof (Manuscript submitted for publication).

Angus Antley and Mel Slater.(2010). The Effect on Lower Spine Muscle Activation

Argelague, F.; Kulik A.; Kunert A.; Andujar, C. and Froehlich, B. See-through techniques for referential awareness in collaborative virtual reality. International Journal of Human-Computer Studies, 69, 6, 387-400.

Augmented Reality. Computers \& Graphics, 35, 4, vii-viii.

Azuma, R.; Billinghurst, M.\& Klinker, G.(2011). Special Section on Mobile

Beaney, D. \& Namee, B. M.(2008). Forked! A Demonstration of Physics Realism in Augmented Reality. 2009 8th IEEE International Symposium on Mixed and Augmented Reality.171-172.

Bideau, B.; Kulpa, R.; Vignais, Nicolas.; Brault, S.; Multon, F. \& Craig, C.(2010). Using Virtual Reality to Analyze Sports Performance. IEEE Computer Graphics and Applications, 30, 2, 14-21.

Billinghurst, M. , Belcher, D., Gupta, A., Kiyokawa K. (2003). Communication Behaviors in Colocated Collaborative AR Interfaces. Computer Interaction 16(3), pp.395-423.

Botella, C.; Bretón-López, J.; Quero, Soledad.; Baños, Rosa.; García-Palacios, A. (2010). Treating Cockroach Phobia With Augmented Reality. Behavior Therapy, 41 (2010), 401-413.

Cáceres, R. \& Ebling, M. (2010). Gaming and Augmented Reality Come to Location- Based Services. Ieee Pervasive Computing (2010), 9, 1, 5-6.

Camera tracking and mapping in multiple regions. Computer Vision and Image

Castle, R.O. \& Murray, D.W.(2011). Keyframe-based recognition and localization during video-rate parallel tracking and mapping. Image and Vision Computing, doi:10.1016/j.imavis.2011.05.002. (Manuscript submitted for publication)

Castle, R.O.; Klein, G. \& Murray, D.W. (2011). Wide-area augmented reality using camera tracking and mapping in multiple regions. Computer Vision and Image Understanding, 115, 854-867.

Chastine, J. W.; Nagel, K.; Zhu, Y \& Yearsovich, L. (2007). Understanding the Design Space of Referencing in Collaborative Augmented Reality Environments. Proceedings of Graphics Interface 2007 on GI 07, 2007, 207-214.

Chiang, H.; Chou, Y.; Chang, L.; Huang, H.; Kuo, F. \& Chen, H. (2011). An Augmented Reality Learning Space for PC DIY. AH '11 Proceedings of the 2nd Augmented Human International Conference, 12. 
Deng, C.; Xue, L. \& Zhou, Z.(2009). Integration of Web2.0, Panorama Virtual Reality and Geological Information System. ICCIT '09 Proceedings of the 2009 Fourth International Conference on Computer Sciences and Convergence Information Technology. 1625-1628.

Dierker, Angelika; Pitsch, Karola; Hermann, Thomas.(2011). An augmented-reality-based scenario for the collaborative construction of an interactive museum. BiPrints Repository, urn:nbn:de:0070-bipr-49260.

Doru Talaba, Imre Horváth, Kwan H Lee.(2010).Special issue of Computer-Aided Design on virtual and augmented reality technologies in product design. Computer-Aided Design, 42, 5, 361-363, DOI: 10.1016/j.cad.2010.01.001.

Dougherty, M. A.; Mann, S. A.; Bronder, M. L.; Bertolami, J. \& Craig, R. M.(2010) Patent application title: Augmented Reality Cloud Computing. Microsoft Corporation, 2010/0257252 A1.

Fernández, C.; Baiget, P.; Roca, F. X. \& Gonzàlez, J.(2011). Augmenting video surveillance footage with virtual agents for incremental event evaluation. Pattern Recognition Letters, 32, 878-889.

GAO, X.; HU, H.; JIA, Q-X.; SUN, H-X. \& SONG, J-Z.(2011). 3D augmented reality teleoperated robot system based on dual vision. The Journal of China Universities of Posts and Telecommunications, $18,1,105-112$.

Gee, A. P.; Webb, M.; Escamilla-Ambrosio, J.; Mayol-Cuevas, W. \& Calway, A. (2011). A topometric system for wide area augmented reality. Computers \& Graphics, 35, 854-868.

Godet-Bar, G.; Rieu, D. \& Dupuy-Chessa, S.(2010). HCI and business practices in a collaborative method for augmented reality systems. Information and Software Technology (2010), 52, 492-505.

Grasset, R.; Dünser, A. \& Billinghurst, M.(2008). Edutainment with a Mixed Reality Book: A visually augmented illustrative childrens' book. Proceedings of the 2008 International Conference on Advances in Computer Entertainment Technology (2008).292-295.

Guan1, T.; Duan, L.; Yu, J.; Chen, Y. and Zhang, X.(2010). Real Time Camera Pose Estimation for Wide Area Augmented Reality Applications. Computer Graphics and Applications, 31, 3, 56-68.

Hachet, M and Kruijff, E.(2010). Guest Editor's Introduction: Special Section on the ACM Symposium on Virtual Reality Software and Technology. IEEE TRANSACTIONS ON VISUALIZATION AND COMPUTER GRAPHICS, 16, 1, 2-3.

Hilsenrat, M. \& Reiner, M.(2010). Hapto-visual Virtual Reality as a Tool in Psychophysical Research on Roughness Sensitivity. ACHI '10 Proceedings of the 2010 Third International Conference on Advances in Computer-Human Interactions, 139-142.

Holmes, N.(2010). The Varieties of Reality. The varieties of reality. Computer, 43,1,96,94-95.

Holz, T.; Campbell, A. G.; O'Hare, G.M.P.; Stafford, J. W.; Martin, A.; Dragone, M.(2011). MiRA-Mixed Reality Agents. J. Journal of Human-Computer Studies, 69 , 251268.

Ishiguro, Y. \& Rekimoto, J.(2011). Peripheral Vision Annotation: Noninterference Information Presentation Method for Mobile Augmented Reality. AH '11 Proceedings of the 2nd Augmented Human International Conference, 8 . 
Ismail, A. W. \& Sunar, M. S.(2009). Collaborative Augmented Reality Approach For Multiuser Interaction in Urban Simulation. ICIMT '09 Proceedings of the 2009 International Conference on Information and Multimedia Technology. 19-23.

Ivetic, D.; Mihic, S.\& Markoski, B.(2010). Augmented AVI video file for road surveying. Computers and Electrical Engineering, 36, 169-179.

Janssen, R .(2011).Augmented Reality -The Ethical Importance of a Shared Context.

Jeferson R. Silva, Thiago T. Santos, Carlos H. Morimoto.(2011). Automatic camera control in virtual environments augmented using multiple sparse videos. Computers \& Graphics , $35,412-421$.

Jiang, X.; Broelemann, K.; Wachenfeld, S. \& Kruger, A.(2011). Graph-based markerless registration of city maps using geometric hashing. Computer Vision and Image Understanding , $115,1032-1043$.

Jo, H.; Hwang, S.; Park, H. \& Ryu, J-H.(2011). Aroundplot: Focus + context interface for offscreen objects in 3Denvironments. Computers \& Graphics, $35,841-853$.

Juan, M. C. \& Pérez, D.(2010). Using augmented and virtual reality for the development of acrophobic scenarios. Comparison of the levels of presence and anxiety. Computers \& Graphics, 34, 6, 756-766.

Kansaku, K.; Hata, N. \& Takano, K.(2010). My thoughts through a robot's eyes: An augmented reality-brain-machine interface. Neuroscience Research, 66, 219-222.

Kato, H. and Billinghurst, M. (1999). Marker tracking and HMD calibration for a videobased augmented reality conferencing system. In IWAR ‘99, pp. 85-94.

Klein, G. and Murray, D. W.(2010). Simulating Low-Cost Cameras for Augmented Reality Compositing. IEEE TRANSACTIONS ON VISUALIZATION AND COMPUTER GRAPHICS,16, 3, 369-380.

Kroeker, K. L.(2010). Mainstreaming Augmented Reality. communications of the acm, 53 ,7, DOI: :10.1145/1785414.1785422

Langlotz, T.; Degendorfer, C.; Mulloni, A.; Schall, G.; Reitmayr, G.; Schmalstieg, D.(2011).Robust detection and tracking of annotations for outdoor augmented reality browsing, Computers \& Graphics , 35 , 831-840.

Leblanc F, Senagore AJ, Ellis CN, Champagne BJ, Augestad KM, Neary PC, Delaney CP \& Colorectal Surgery Training Group.(2010). Hand-assisted laparoscopic sigmoid colectomy skills acquisition: augmented reality simulator versus human cadaver training models. Journal Of Surgical Education (2010), 67, 4, 200-204.

Lee, H. S \& Lee, J. W.(2008). Mathematical Education Game Based on Augmented Reality. Lecture Notes in Computer Science, 2008, Volume 5093/2008, 442450, DOI: 10.1007/978-3-540-69736-7_48.

Lee, J, Han, S, Yang, J. (2011). Construction of a computer-simulated mixed reality environment for virtual factory layout planning. Computers in Industry , 62, 8698.

Li, S. \& Xu, C. (2011). Efficient lookup table based camera pose estimation

Li, S.(2010). Research on Network Cooperative Learning System Based on Virtual Reality. IC4E '10 Proceedings of the 2010 International Conference on e-Education, eBusiness, e-Management and e-Learning, 43-46.

Lievonen, M.; Rosenberg, D.; Dörner, R.; Kühn, G. \& Walkowski, S.(2009). Augmented Reality as Means for Creating Shared Understanding. ECCE '09 European 
Conference on Cognitive Ergonomics: Designing beyond the Product --Understanding Activity and User Experience in Ubiquitous Environments, 17.

Livingston, M. A.; Azuma, R. T.; Bimber, O. \& Saito, H.(2010). Guest Editors' Introduction: Special Section on The International Symposium on Mixed and Augmented Reality (ISMAR). IEEE TRANSACTIONS ON VISUALIZATION AND COMPUTER GRAPHICS, 16, 3, 353 - 354.

Martin, S.; Diaz, Gabriel; Sancristobal, E.; Gil, R.; Castro, M. \& Peire, J.(2011). New technology trends in education: Seven years of forecasts and convergence. Computers \& Education, 57, 1893-1906.

McCall, R.; Wetzel, R.; Lo“schner, h.; Braun, A-K.(2011). Using presence to evaluate an augmented reality location aware game. Personal and Ubiquitous Computing, 15, 1, 25-35.

Morrison, A.; Mulloni, A.; Lemmelä, S.; Oulasvirta, A.; Jacucci, G.; Peltonen, P.; Schmalstieg, D. \& Regenbrecht, H.(2011).Collaborative use of mobile augmented reality with paper maps. Computers \& Graphics , 35 , 789-799.

Nilsson, S.; Johansson, B. \& Jonsson, A.(2009). Using AR to support cross-organisational collaboration in dynamic tasks. ISMAR '09 Proceedings of the 2009 8th IEEE International Symposium on Mixed and Augmented Reality, 3-12.

Ong, S.K. \& Wang, Z.B.(2011). Augmented assembly technologies based on 3D bare-hand interaction. CIRP Annals - Manufacturing Technology, 60 ,1-4.

Paelke, V. \& Sester, Monika.(2010). Augmented paper maps: Exploring the design space of a mixed reality system. ISPRS Journal of Photogrammetry and Remote Sensing, 65, 256-265.

Pecchioli, L.; Carrozzino, M.; Mohamed, F.; Bergamasco, M \& Kolbe, T. H.(2011).ISEE: Information access through the navigation of a 3D interactive environment. Journal of Cultural Heritage, 2011/02/25, doi:10.1016/j.culher.2010.11.001.

Peter Meier, CTO, metaio GmbH.(2010). Mobile Augmented Reality 2010. metaio AUGMENTED SOLUTIONS, 01/2010.

Phan, V. T. \& Choo, S. Y.(2009). A Combination of Augmented Reality and Google Earth's facilities for urban planning in idea stage. International Journal of Computer Applications, 4, 3, 26-34.

Pintaric ,T. \& Kaufmann, H.(2007). Affordable Infrared-Optical Pose-Tracking for Virtual and Augmented Reality. IEEE VR Workshop on Trends and Issues in Tracking for Virtual Environments. 2007/03/14 - 2007/03/17,44 - 51.

Polys, N. F.; Bowman, Doug A. \& North, Chris.(2011). The role of Depth and Gestalt cues in information-rich virtual environments. Journal of Human-Computer Studies, 69 , 30-51.

Portalés, C.; Lerma , J. L. \& Navarro, S.(2010). Augmented reality and photogrammetry: A synergy to visualize physical and virtual city environments. ISPRS Journal of Photogrammetry and Remote Sensing (2010) ,65, 1, 134-142.

Quy, PS.; Lee, J.; Kim, JH.; Kim, JI. \& Kim, HS.(2009). Collaborative Experiment and Education based on Networked Virtual Reality. 2009 Fourth International Conference on Computer Sciences and Convergence Information Technology. ICCIT '09 Proceedings of the 2009 Fourth International Conference on Computer Sciences and Convergence Information Technology, 80- 85. 
Rosenblum, L. \& Julier, S. (2007). Action- and Workflow-Driven Augmented Reality for Computer-Aided Medical Procedures. IEEE Computer Society, September/October (2007), 10-14.

Samset, E.; Schmalstieg, D.; Vander Sloten, J.; Freudenthal, A.; Declerck, J.; Casciaro, S.; Rideng, O. \& Gersak, B.(2008). Augmented Reality in Surgical Procedures. Human Vision and Electronic Imaging XIII.

Sayed, N. A.M. El.; Zayed, H. H.; Sharawy, M. I.(2011). ARSC: Augmented reality student card An augmented reality solution for the education field. Computers \& Education, $56,1045-1061$.

Sayed, N.A.M., El, Zayed, H. H., Sharawy, M.I.(2011). ARSC: Augmented reality student card An augmented reality solution for the education field. Computers \& Education, 56, 1045-1061.

Shen, Y.; Ong, S. K. \& Nee, A. Y. C.(2008). Augmented reality for collaborative product design and development. Design Studies (2010), 31, 2, 118-145.

Shen, Y.; Ong, S. K. \& Nee, A. Y. C. (2011).Vision-Based Hand Interaction in Augmented Reality Environment. International Journal of Human-Computer Interaction, 27 ,6, 523-544.

Shin, D. H. \& Dunston, P. S.(2010). Technology development needs for advancing Augmented Reality-based inspection. Automation in Construction, 19 (2010), 169182.

Silva, R.; Giraldi, G. \& Oliveira, Jauvane C.(2003). Introduction to augmented reality. Technical Report: 25/2003, LNCC, Brazil, 2003.

Taketomi, T.; Sato T. \& Yokoya, N. (2011). Real-time and accurate extrinsic camera parameter estimation using feature landmark database for augmented reality. Computers \& Graphics, 35, 768-777.

Uva, A.E.; Cristiano, S.; Fiorentino, M. \& Monno, G.(2010). Distributed design review using tangible augmented technical drawings. Computer-Aided Design, 42, 364-372.

Walsh, J. A. \& Thomas, B. H.(2011). Visualising Environmental Corrosion in Outdoor Augmented Reality School of Computer and Information Science University of South Australia.

Wang, H. S. (1999). The system design of on-line virtual reality courseware in computer assembly, Journal of Secondary Education, 6, 355-386

Wang, H. S. (2000). The study of using virtual reality software in art curriculum, Journal of Secondary Education, 7, 173-200

Wang, Y.; Shen, Y.; Liu, D.; Wei, S. \& Zhu, C.(2010). Key Technique of Assembly System in an Augmented Reality Environment. ICCMS '10 Proceedings of the 2010 Second International Conference on Computer Modeling and Simulation, 1, 133-137.

Wither, J.; Tsai, Y-T. \&Azuma, R. (2011). Indirect augmented reality. Computers \& Graphics, $35,810-822$

Wrzesien, Maja.; Burkhardt,J-M.; Raya,M.A.\& Botella, C.(2011). Mixing Psychology and HCI in Evaluation of Augmented Reality Mental Health Technology. CHI EA '11 Proceedings of the 2011 annual conference extended abstracts on Human factors in computing systems, 2119-2124, doi:10.1145/1979742.1979898.

Yabuki, N.; Miyashita, K. \& Fukuda, T.(2011). An invisible height evaluation system for building height regulation to preserve good landscapes using augmented reality. Automation in Construction, 20, 228-235. 
Yim, H. B. \& Seong, P. H. (2010). Heuristic guidelines and experimental evaluation of effective augmented-reality based instructions for maintenance in nuclear power plants. Nuclear Engineering and Design, 240, 4096-4012.

Zhang, J.; Ong, S.K. \& Nee, A.Y.C. (2011). System in an augmented reality environment. International Journal of Production Research, 49, 13, 3919-3938.

Zhang, J.; Ong, S.K. \& Nee, A.Y.C.(2010). A multi-regional computation scheme in an ARassisted in situ CNC simulation environment. Computer-Aided Design, 42, 11671177.

Ziaei, Z.; Hahto, A.; Mattila, J.; Siuko, M. \& Semeraro, L.(2011). Real-time markerless Augmented Reality for Remote Handling system in bad viewing conditions. Fusion Engineering and Design, 18/02/2011, doi:10.1016/j.fusengdes.2010.12.082. 


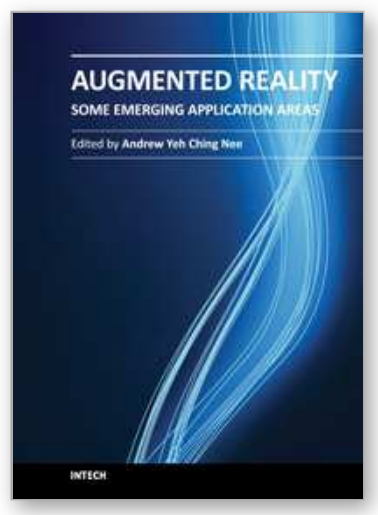

\author{
Augmented Reality - Some Emerging Application Areas \\ Edited by Dr. Andrew Yeh Ching Nee
}

ISBN 978-953-307-422-1

Hard cover, 266 pages

Publisher InTech

Published online 09, December, 2011

Published in print edition December, 2011

Augmented Reality (AR) is a natural development from virtual reality (VR), which was developed several decades earlier. AR complements VR in many ways. Due to the advantages of the user being able to see both the real and virtual objects simultaneously, AR is far more intuitive, but it's not completely detached from human factors and other restrictions. AR doesn't consume as much time and effort in the applications because it's not required to construct the entire virtual scene and the environment. In this book, several new and emerging application areas of $A R$ are presented and divided into three sections. The first section contains applications in outdoor and mobile AR, such as construction, restoration, security and surveillance. The second section deals with AR in medical, biological, and human bodies. The third and final section contains a number of new and useful applications in daily living and learning.

\title{
How to reference
}

In order to correctly reference this scholarly work, feel free to copy and paste the following:

Hsiao-shen Wang and Chih-Wei Chiu (2011). The Design and Implementation of On-Line Multi-User Augmented Reality Integrated System, Augmented Reality - Some Emerging Application Areas, Dr. Andrew Yeh Ching Nee (Ed.), ISBN: 978-953-307-422-1, InTech, Available from:

http://www.intechopen.com/books/augmented-reality-some-emerging-application-areas/the-design-andimplementation-of-on-line-multi-user-augmented-reality-integrated-system

\section{INTECH}

open science | open minds

\section{InTech Europe}

University Campus STeP Ri

Slavka Krautzeka 83/A

51000 Rijeka, Croatia

Phone: +385 (51) 770447

Fax: +385 (51) 686166

www.intechopen.com

\section{InTech China}

Unit 405, Office Block, Hotel Equatorial Shanghai

No.65, Yan An Road (West), Shanghai, 200040, China

中国上海市延安西路65号上海国际贵都大饭店办公楼 405 单元

Phone: +86-21-62489820

Fax: $+86-21-62489821$ 
(C) 2011 The Author(s). Licensee IntechOpen. This is an open access article distributed under the terms of the Creative Commons Attribution 3.0 License, which permits unrestricted use, distribution, and reproduction in any medium, provided the original work is properly cited. 